\title{
Observation of saltation activity at Tazhong area in Taklimakan Desert, China
}

\author{
XingHua YANG ${ }^{1,2}$, Ali MAMTIMIN ${ }^{1,2}$, Qing $\mathrm{HE}^{1,2 *}$, XinChun $\mathrm{LIU}^{1,2}$, Wen HUO $\mathrm{H}^{1,2}$ \\ ${ }^{1}$ Institute of Desert Meteorology, China Meteorological Administration, Urumqi 830002, China; \\ ${ }^{2}$ Desert Atmosphere and Environment Observation Experiment of Taklimakan Station, Tazhong 841000, China
}

\begin{abstract}
A two-year field observation of saltation activity was carried out at Tazhong area, the hinterland area of the Taklimakan Desert with highly frequent dust storms. From 1 September 2008 to 31 August 2010, a piezoelectric saltation sensor (Sensit) was used to continuously collect the data on saltation activity at a level sand surface. Analysis on the data suggests that saltation activity can occur at any time of the year when conditions are favorable; however, the necessary conditions are rarely satisfied in most time. In the daytime of spring or summer, saltation activity can persist even over a continuous one-hour-or-so period. It is found that, from 1 September 2008 to 31 August 2010 , saltation activity accounts for more than $3 \%$ of the total yearly time, and it tends to peak in spring and summer months with strong winds. During winter months when winds are weak, however, it is often at a minimum. It seems that precipitation does not appear to be significant in reducing saltation activity in arid regions like Tazhong.
\end{abstract}

Keywords: saltation activity; aeolian sand transport; piezoelectric saltation sensor (Sensit); Tazhong; Taklimakan Desert

Citation: XingHua YANG, Ali MAMTIMIN, Qing HE, XinChun LIU, Wen HUO. 2013. Observation of saltation activity at Tazhong area in Taklimakan Desert, China. Journal of Arid Land, 5(1): 32-41.

Aeolian sand transport is a serious problem in many arid regions in the world, and it is considered to be a significant part of global biogeochemical cycles (McTainsh et al., 2007; Liu, 2009). Saltation, a mode of airborne particle motion in the atmosphere, plays a key role in aeolian sand transport studies (Schönfeldt and von Löwis, 2003). The transportation of most aeolian sediments due to wind erosion is by means of saltation (Bagnold, 1941; Chepil, 1945).

Many researches on saltation have been carried out under ideal and controllable conditions including the wind tunnel experiment, theoretical analysis and numerical simulation (van Boxel et al., 1999; Zou et al., 2001; Zhou et al., 2002; Zheng et al., 2003; Zheng et al., 2004; Leenders et al., 2005; Zheng et al., 2006; Huang et al., 2007; Shao, 2008), and under natural field conditions including direct observation (Bagnold, 1941; Chepil, 1945), measurement of saltation sediment discharge (Gillette and Walker, 1977; Nickling,
1983; Leys and McTainsh, 1996), and small-scale aeolian sand transport measurement with impact recording devices such as Sensits and saltiphones (Gillette et al., 1997; Sterk and Spaan, 1997; Stout, 2003, 2010; Yang et al., 2011, 2012).

Wind tunnel and field experiments have improved our understanding of saltation and aeolian transport mechanisms under controllable conditions and unsteady wind conditions. However, further investigations are required, especially under complex field conditions.

An experiment to monitor saltation activity with the piezoelectric saltation sensor (Sensit) was developed from 1 September 2008 to 31 August 2010 in Tazhong, the hinterland of the Taklimakan Desert. The piezoelectric saltation sensor (Sensit) is an electronic device based on a sensible diode which can count impacts of saltation sand particles. This device has been used to monitor the saltation movement in many field experi-

\footnotetext{
*Corresponding author: Qing HE (E-mail: qinghe@idm.cn) Received 2012-03-10; revised 2012-07-13; accepted 2012-08-22

(C) Xinjiang Institute of Ecology and Geography, Chinese Academy of Sciences, Science Press and Springer-Verlag Berlin Heidelberg 2013
} 
ments (Fryrear, 1995; Gillette, 1997; Stout and Zobeck, 1997; Stout, 2003, 2007, 2010; de Oro and Buschiazzo, 2009). In this paper, the characteristics of sand saltation activity and its relation with meteorological elements were analyzed based on the measured data, so as to gain new understanding of saltation activity and dust emissions and try to forecast and guard against the occurrence of windblown sand or sandstorms in the Taklimakan Desert.

\section{Study area}

The Taklimakan Desert, located in the central part of the Tarim Basin in Xinjiang Uygur autonomous region, Northwest China (Fig.1), is the second largest shifting sand desert in the world, with about $85 \%$ of shifting sand dunes (Sun and Liu, 2006). As an area where sandstorms occur frequently, it is known as an important sand-dust source in China (Wang et al., 2000; Qian et al., 2002; Zhou et al., 2002). Sandstorms caused by soil wind erosion in this region have produced great effects on the climatic change in East Asia (Zhao et al., 2006).

We took Tazhong as the research site for the saltation activity observation experiment. It is $220 \mathrm{~km}$ from the desert edge. The climate is very dry, with an annual precipitation of $25.0 \mathrm{~mm}$ and over 100 sandblowing days per year. Vegetation is sparse, with about $90 \%$ of the area being occupied by sandy desert.
The site chosen for observation in this study is a level shifting sand surface. Laboratory test results show that the Sensit-H11LIN can not respond to suspended dust (lower than $50 \mu \mathrm{m}$ ) (Sensit Company, 2007), so twenty-one samples of surface sand (including dune sand and flat sandy land sand) were obtained from the site and its surrounding area, and were measured to obtain the grain size distribution. The results show that these sands are mainly 'fine sand' and 'very fine sand' with an average grain size of 147 $\mu \mathrm{m}$, with about $0.3 \%$ of the grains smaller than $50 \mu \mathrm{m}$.

\section{Monitoring methods}

The period from 1 September 2008 to 31 August 2010, except the time from 27 October to 15 November 2009 and from 26 December 2009 to 6 January 2010, was selected for measurement, covering a period of twenty three months.

An instrument system was set up at the observation site, which consists of a 2-m tall meteorological tower, two piezoelectric saltation sensors (Sensit) and a data collector (CR1000, Campbell) (Fig. 2). The wind speed inspectors (WAA151, Vaisala) were mounted at the heights of $5,10,20,50,100$ and $200 \mathrm{~cm}$, respectively. To measure relative humidity, air temperature sensors (HMP45D, Vaisala) were mounted at a height of $1.5 \mathrm{~m}$ above the surface. All meteorological variables were measured at a frequency of $1 \mathrm{~Hz}$ and the

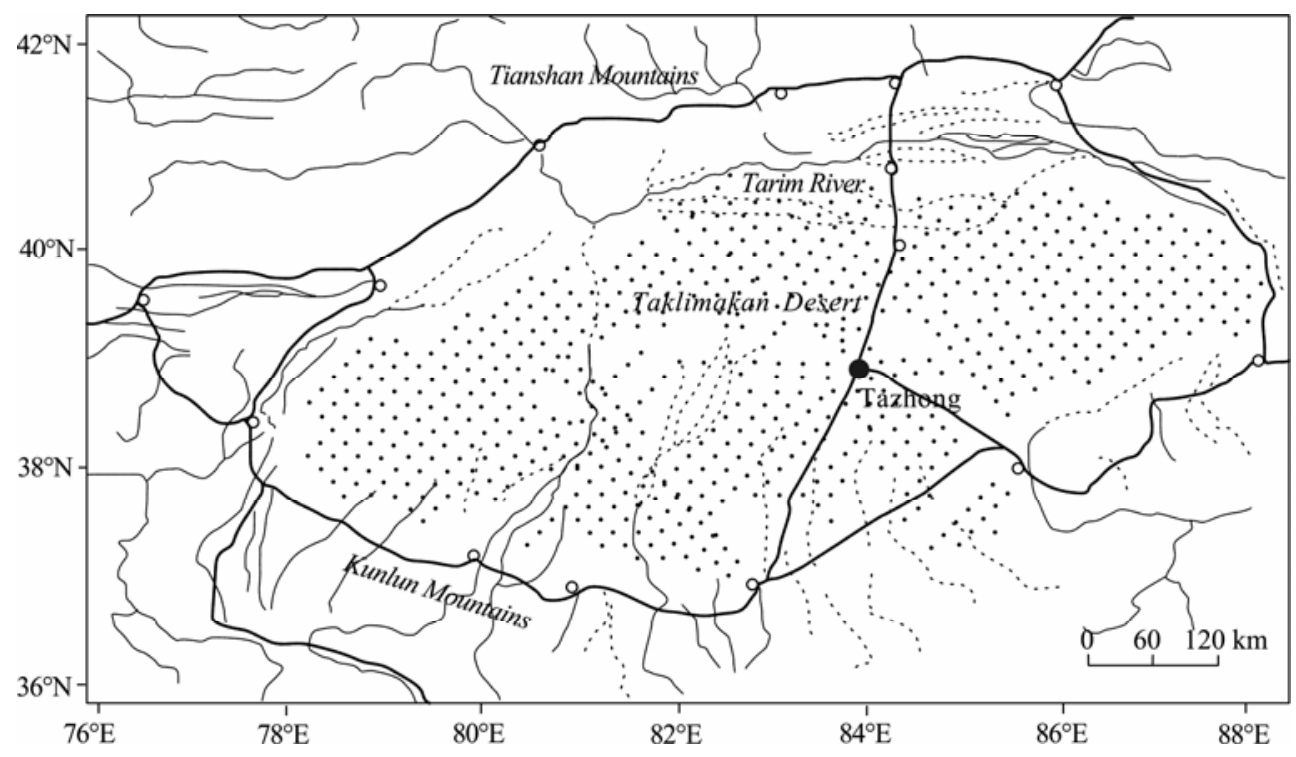

Fig. 1 Location of the Taklimakan Desert in the Tarim Basin; Tazhong is located at the center of the desert. 


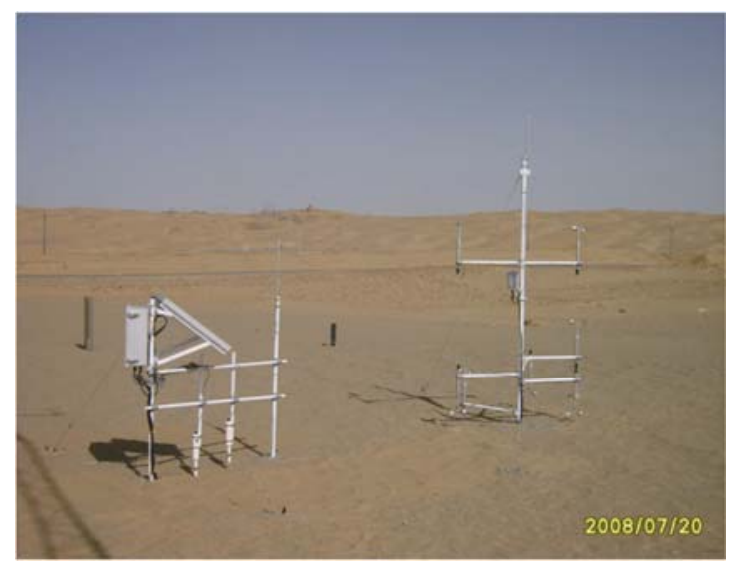

Fig. 2 The 2-m meteorological tower and piezoelectric saltation sensors (Sensit)

values were averaged at an hourly interval.

Saltation activity was monitored with piezoelectric saltation sensors (Sensit). The Sensit can produce a pulse signal each time. The transducer is impacted by a saltating sand particle, and the transducer area is 17 $\mathrm{cm}^{2}$ (with a width of $2 \mathrm{~cm}$, and a perimeter of $8.5 \mathrm{~cm}$ ). During the periods of active saltation, the piezoelectric transducer produced a series of signals that were used simply as on-or-off indicators of saltation activity. Each pulse signal generated by each particle impact was detected, and if one or more impacts were detected during a given second, then that second was registered as one 'saltation second' (Stout, 2003). At the end of each hour time, the total number of saltation seconds were summed and outputted into the data collector. As measured by Stout $(2003,2007)$ and Sankey et al. (2009), the transducers of the Sensit were located about $5 \mathrm{~cm}$ above the surface. In this study, the transducers were located $5 \mathrm{~cm}$ and $10 \mathrm{~cm}$ above the surface, and the data at the height of $5 \mathrm{~cm}$ was used to analyze the variation of saltation activity.

Saltation activity is expressed as a dimensionless ratio of the total number of saltation seconds divided by the total number of seconds within the period of measurement (Stout, 2003). Thus, the hourly saltation activity is simply the hourly total saltation seconds divided by 3,600 seconds. Using the same data, the daily, monthly, seasonal or yearly saltation activity can also be calculated.

\section{Results}

\subsection{Hourly saltation activity}

Measured hourly saltation activity values were plotted in Fig. 3. The data provide a continuous saltation activity at the observation site from 1 September 2008 to 31 August 2010.

Saltation activity appears to be quite intermittent. Recent research suggested that saltation is often an unsteady and intermittent process because winds are highly unsteady under natural conditions (Stout and Zobeck, 1997; Sterk et al., 1998; Stout, 2003, 2010). The highly intermittent nature of saltation suggests that the necessary conditions are not always satisfied for aeolian transport. For the whole period from 1 September 2008 to 31 August 2010, 66\% of the measured hours have no detected saltation activity, and the detected no saltation activity hours occupy a little less than $93 \%$ at Yellow Lake (Stout, 2003). The field experiment in this study proves that sand blowing events in the Taklimakan Desert occur more frequently than reported in the previous studies.

Saltation is often unsteady. However, during some sand blowing events, the hourly saltation activity reaches or approximates unity, indicating a continuous or nearly continuous aeolian transport over a one-hour period. The highest values of hourly saltation activity measured during this experiment are listed in Table 1. The highest value, 1.0, was recorded at 12:00 LST (Local Standard Time) on 10 March 2009, and at 13:00 LST on 29 April 2009. During the same two days there are another twelve hours with saltation activity greater than 0.9 . Overall there are a total of 72 values of hourly saltation activity greater than 0.9 from 1 September 2008 to 31 August 2010. The highest value measured by Stout (2003) on a high plains is only 0.96 and there have only been a total of 20 values of hourly saltation activity greater than 0.9 in a four-year experiment, which indicates that sand blowing events occur more easily at Tazhong.

From Table 1, we can find that the top 72 hourly values occurred during March, April, May, June, July, September and October, and all of the top 72 hourly values were recorded during daylight hours between 

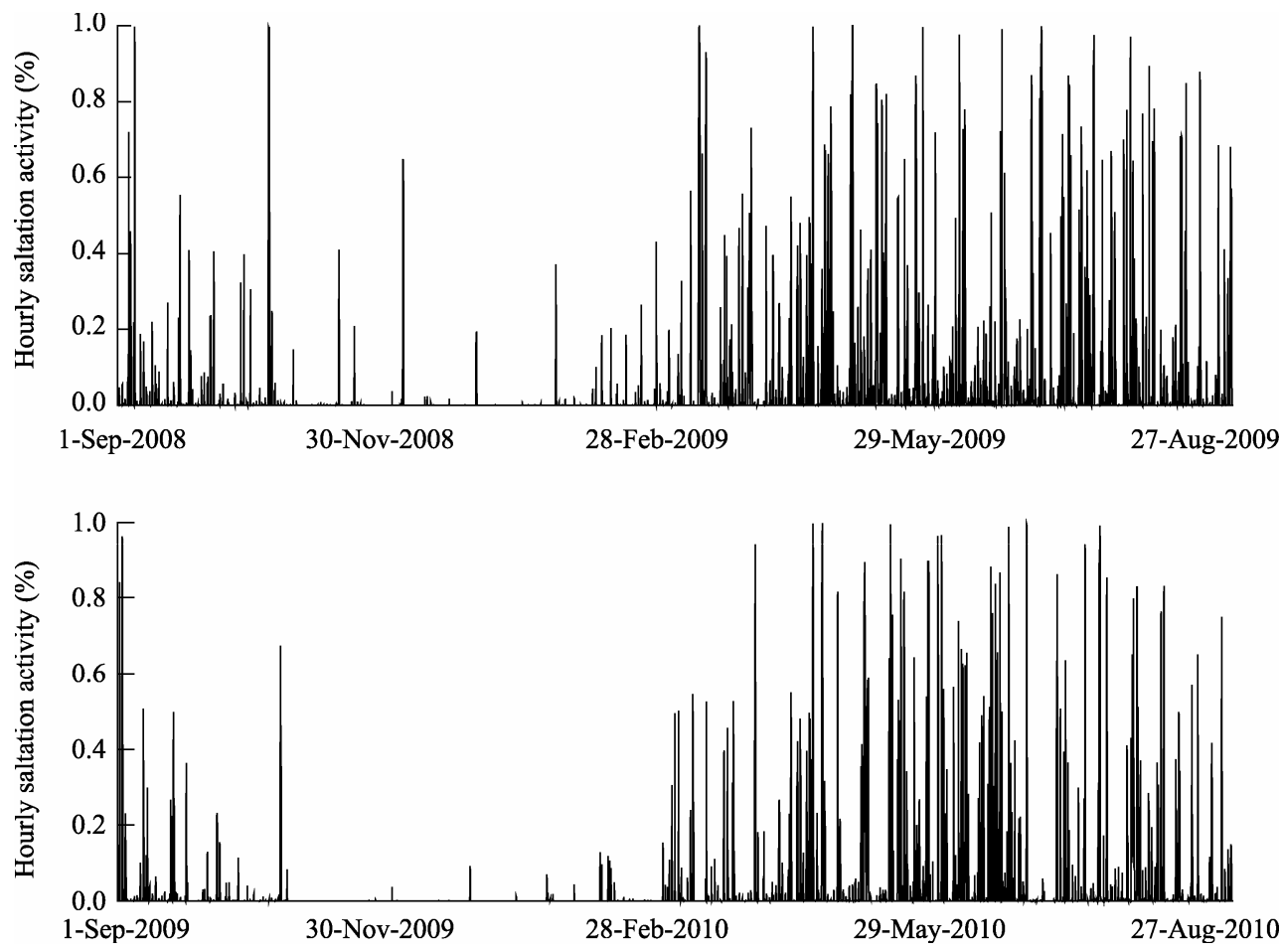

Fig. 3 Hourly saltation activity measured at Tazhong

Table 1 Top 72 values of hourly saltation activity measured at Tazhong from 1 September 2008 to 31 August 2010

\begin{tabular}{|c|c|c|c|c|c|c|c|c|c|c|c|}
\hline Rank & Date & Time & $\begin{array}{l}\text { Hourly } \\
\text { saltation } \\
\text { activity }\end{array}$ & Rank & Date & Time & $\begin{array}{c}\text { Hourly } \\
\text { saltation } \\
\text { activity }\end{array}$ & Rank & Date & Time & $\begin{array}{c}\text { Hourly } \\
\text { saltation } \\
\text { activity }\end{array}$ \\
\hline 1 & 10-Mar-2009 & $12: 00$ & 1.000 & 25 & 17-Jun-2009 & $13: 00$ & 0.991 & 49 & 30-Jun-2009 & 08:00 & 0.953 \\
\hline 2 & 29-Apr-2009 & $13: 00$ & 1.000 & 26 & 25-Jun-2010 & $16: 00$ & 0.990 & 50 & 03-Jun-2009 & $15: 00$ & 0.948 \\
\hline 3 & 10-Mar-2009 & 11:00 & 1.000 & 27 & 19-Jun-2010 & $17: 00$ & 0.989 & 51 & 30-Jun-2009 & $14: 00$ & 0.943 \\
\hline 4 & 29-Apr-2009 & $14: 00$ & 1.000 & 28 & 19-Jul-2010 & $16: 00$ & 0.989 & 52 & 28-Mar-2010 & $18: 00$ & 0.942 \\
\hline 5 & 10-Mar-2009 & $13: 00$ & 0.999 & 29 & 20-Oct-2008 & $17: 00$ & 0.988 & 53 & 14-Jul-2010 & $19: 00$ & 0.942 \\
\hline 6 & 30-Jun-2009 & $12: 00$ & 0.999 & 30 & 16-Apr-2009 & $17: 00$ & 0.986 & 54 & 29-Apr-2009 & $16: 00$ & 0.940 \\
\hline 7 & 19-Apr-2010 & $17: 00$ & 0.998 & 31 & 16-Apr-2010 & $17: 00$ & 0.986 & 55 & 29-Apr-2009 & $11: 00$ & 0.938 \\
\hline 8 & 06-Sep-2008 & $16: 00$ & 0.997 & 32 & 19-Jul-2010 & $14: 00$ & 0.985 & 56 & 29-Jul-2009 & $15: 00$ & 0.938 \\
\hline 9 & 16-Apr-2009 & $16: 00$ & 0.997 & 33 & 25-Jun-2010 & $14: 00$ & 0.978 & 57 & 02-Sep-2009 & $15: 00$ & 0.936 \\
\hline 10 & 16-Apr-2010 & $16: 00$ & 0.997 & 34 & 03-Jun-2009 & $16: 00$ & 0.977 & 58 & 17-Jul-2009 & $14: 00$ & 0.936 \\
\hline 11 & 29-Apr-2009 & $12: 00$ & 0.997 & 35 & 30-Jun-2009 & $13: 00$ & 0.975 & 59 & 17-Jul-2009 & $17: 00$ & 0.931 \\
\hline 12 & $20-O c t-2008$ & $11: 00$ & 0.996 & 36 & 17-Jul-2009 & $16: 00$ & 0.975 & 60 & 12-Mar-2009 & $15: 00$ & 0.929 \\
\hline 13 & 22-Мау-2009 & $16: 00$ & 0.996 & 37 & 16-Apr-2009 & $15: 00$ & 0.974 & 61 & 25-Jun-2010 & $17: 00$ & 0.926 \\
\hline 14 & $20-O c t-2008$ & $14: 00$ & 0.996 & 38 & 16-Apr-2010 & $15: 00$ & 0.974 & 62 & 30-Jun-2009 & 07:00 & 0.925 \\
\hline 15 & 25-Jun-2010 & $15: 00$ & 0.996 & 39 & 19-Jul-2010 & $13: 00$ & 0.971 & 63 & 30-Jun-2009 & $10: 00$ & 0.921 \\
\hline 16 & 10-Mar-2009 & 09:00 & 0.995 & 40 & 29-Jul-2009 & $14: 00$ & 0.971 & 64 & 17-Jul-2009 & $15: 00$ & 0.920 \\
\hline 17 & 30-Jun-2009 & $11: 00$ & 0.995 & 41 & 28-May-2010 & $18: 00$ & 0.966 & 65 & 30-Jun-2009 & $15: 00$ & 0.920 \\
\hline 18 & $20-O c t-2008$ & $15: 00$ & 0.994 & 42 & 10-Mar-2009 & 08:00 & 0.964 & 66 & 06-Sep-2008 & $17: 00$ & 0.918 \\
\hline 19 & 12-May-2010 & 02:00 & 0.994 & 43 & 27-May-2010 & $13: 00$ & 0.964 & 67 & 12-Mar-2009 & $16: 00$ & 0.912 \\
\hline 20 & 29-Apr-2009 & $15: 00$ & 0.994 & 44 & 02-Sep-2009 & $13: 00$ & 0.963 & 68 & 19-Jul-2010 & $12: 00$ & 0.906 \\
\hline 21 & $20-O c t-2008$ & $13: 00$ & 0.993 & 45 & 10-Mar-2009 & $14: 00$ & 0.961 & 69 & 16-Apr-2009 & $19: 00$ & 0.904 \\
\hline 22 & $20-$ Oct- 2008 & $12: 00$ & 0.992 & 46 & 19-Apr-2010 & $18: 00$ & 0.959 & 70 & 16-Apr-2010 & $19: 00$ & 0.904 \\
\hline 23 & 10-Mar-2009 & 10:00 & 0.991 & 47 & 02-Sep-2009 & $14: 00$ & 0.957 & 71 & 10-Mar-2009 & $15: 00$ & 0.903 \\
\hline 24 & 19-Jul-2010 & $15: 00$ & 0.991 & 48 & 19-Apr-2010 & $16: 00$ & 0.953 & 72 & 15-May-2010 & $12: 00$ & 0.902 \\
\hline
\end{tabular}


07:00 and 19:00 LST, with only one being recorded at 02:00 LST. The result shows that strong sand blowing events are more likely to occur during the day in spring, summer and autumn. In those periods, the necessary conditions for aeolian transport are more easily satisfied. The statistic results show that 53 of the 72 top values appeared on sandstorm days, including all the top 5 values, which indicates that sandstorms always cause serious aeolian sand transport.

\subsection{Daily saltation activity}

Daily saltation activity values were plotted in Fig. 4, and daily saltation activity was calculated by summing all saltation seconds within a single day and then dividing the sum by 86,400 seconds.

The distribution pattern of saltation activity was not remarkably changed with the variation in the time scale from hour to day. However, the daily saltation activity values were typically much lower than the hourly values. Extreme values of hourly saltation activity occasionally reached or approached unity, whereas peak values of daily saltation activity rarely exceeded 0.5 . The 20 highest values of daily saltation activity recorded during this experiment were listed in Table 2. The highest value, 0.503 , was recorded on 30 Jun 2009, and the second highest value, 0.476, was recorded on 19 July 2010 , and 12 of the 20 top values appeared on sandstorm days, including all the top 10 values except the sixth. For the two years from 1 September 2008 to 31 August 2010, 4.3\% of all the measured days have daily saltation activity greater than 0.2 , and $12.2 \%$ greater than 0.1 , which is much higher than $1.5 \%$. The percentage with daily saltation activity values is greater than 0.1 , which was measured at Yellow Lake (Stout, 2003).
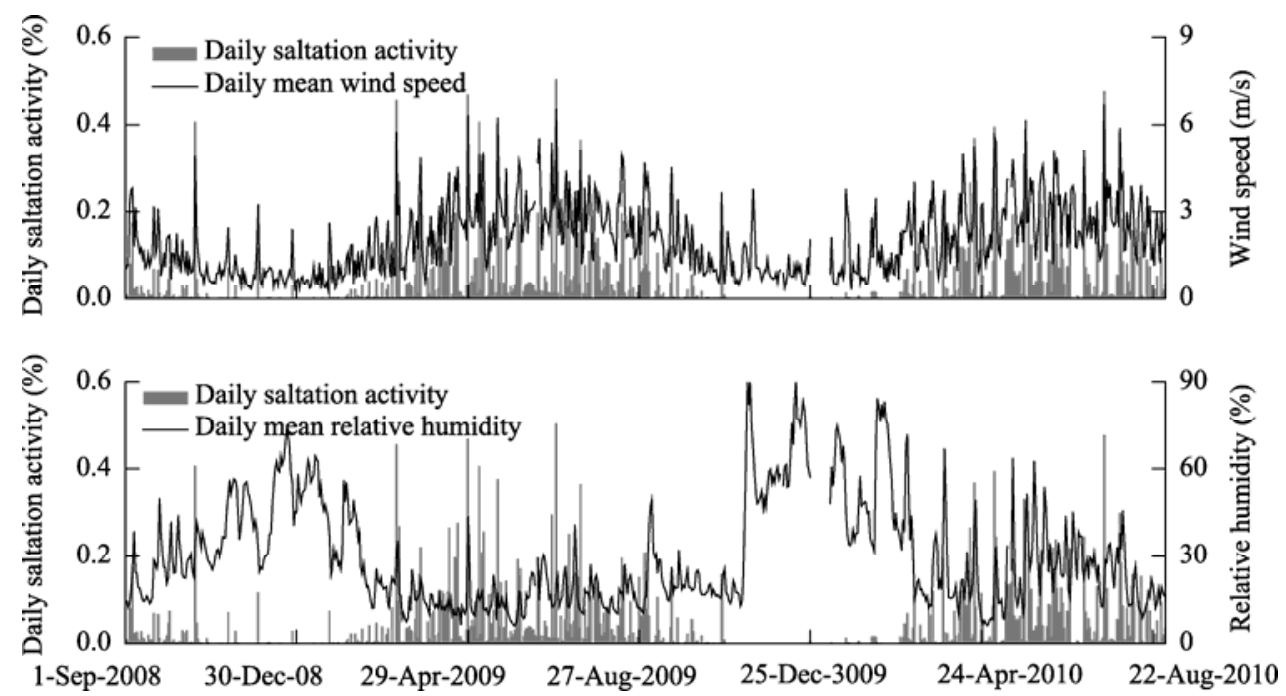

Fig. 4 Daily saltation activity, daily mean wind speed at $2 \mathrm{~m}$ and relative humidity at $1.5 \mathrm{~m}$ measured at Tazhong

Table 2 Top 20 values of daily saltation activity measured at Tazhong from 1 September 2008 to 31 August 2010

\begin{tabular}{|c|c|c|c|c|c|}
\hline Rank & Date & Daily saltation activity & Rank & Date & Daily saltation activity \\
\hline 1 & 30-Jun-2009 & 0.503 & 11 & 24-May-2010 & 0.331 \\
\hline 2 & 19-Jul-2010 & 0.476 & 12 & 30-Jul-2010 & 0.299 \\
\hline 3 & 29-Apr-2009 & 0.468 & 13 & 27-Jun-2009 & 0.294 \\
\hline 4 & 10-Mar-2009 & 0.455 & 14 & 22-Apr-2009 & 0.275 \\
\hline 5 & 20-Oct-2008 & 0.406 & 15 & 12-Mar-2009 & 0.267 \\
\hline 6 & 07-May-2009 & 0.405 & 16 & 16-Apr-2009 & 0.265 \\
\hline 7 & 03-May-2010 & 0.394 & 17 & 16-Apr-2010 & 0.265 \\
\hline 8 & 20-Мay-2009 & 0.376 & 18 & 10-Мay-2009 & 0.254 \\
\hline 9 & 19-Apr-2010 & 0.368 & 19 & 09-Jul-2009 & 0.250 \\
\hline 10 & 17-Jul-2009 & 0.364 & 20 & 04-Мay-2010 & 0.243 \\
\hline
\end{tabular}


Variations in saltation activity reflect the changes in environmental conditions. The important environmental factors such as daily wind speed, relative humidity were plotted in Fig. 4. Wind speed followed an annual cycle with typical peaks during spring and summer; and during late autumn and winter the wind speed tended to be at a low point. Accordingly, high-level saltation activity occurred in the spring and summer, and generally low-level saltation activity occurred in the late autumn and winter. There is a typical power function relationship between saltation activity and wind speed, and the correlation coefficient $R^{2}$ is 0.69 . Variation of the daily relative humidity was just contrary to wind speed, and it tended to be at a low point during spring and summer and at a peak point during late autumn and winter. The research shows that threshold wind speed depends significantly on air humidity in air-dry soils (McKenna-Neuman, 2003; Ravi et al., 2004; Ravi and D'Odorico, 2005; Mckenna-Neuman and Sanderson, 2008; Sankey et al., 2009), and the critical threshold declines with de- creasing values of relative humidity (Ravi et al., 2004; Ravi and D'Odorico, 2005). So, in the study area, the critical threshold would keep at a relatively low level during spring and summer, which is beneficial to the occurrence of saltation activity combining with high wind speeds.

\subsection{Monthly saltation activity}

Monthly saltation activity values and its relationship with wind speed, precipitation, sandstorm days and occurrence time of sandstorm were plotted in Fig. 5. The monthly saltation activity values were much lower than hourly and daily values. The highest value, 0.081, was recorded in May 2010. Clearly, saltation activity seldom accounts for more than $10 \%$ of the time in any month. Saltation activity at Tazhong mainly occurs in April, May, June and July and these months accounts for $67.2 \%$ of the total two years.

Figure 5 shows that monthly saltation activity is strongly correlated with wind speed, and poorly correlated with precipitation, sandstorm days and occur-
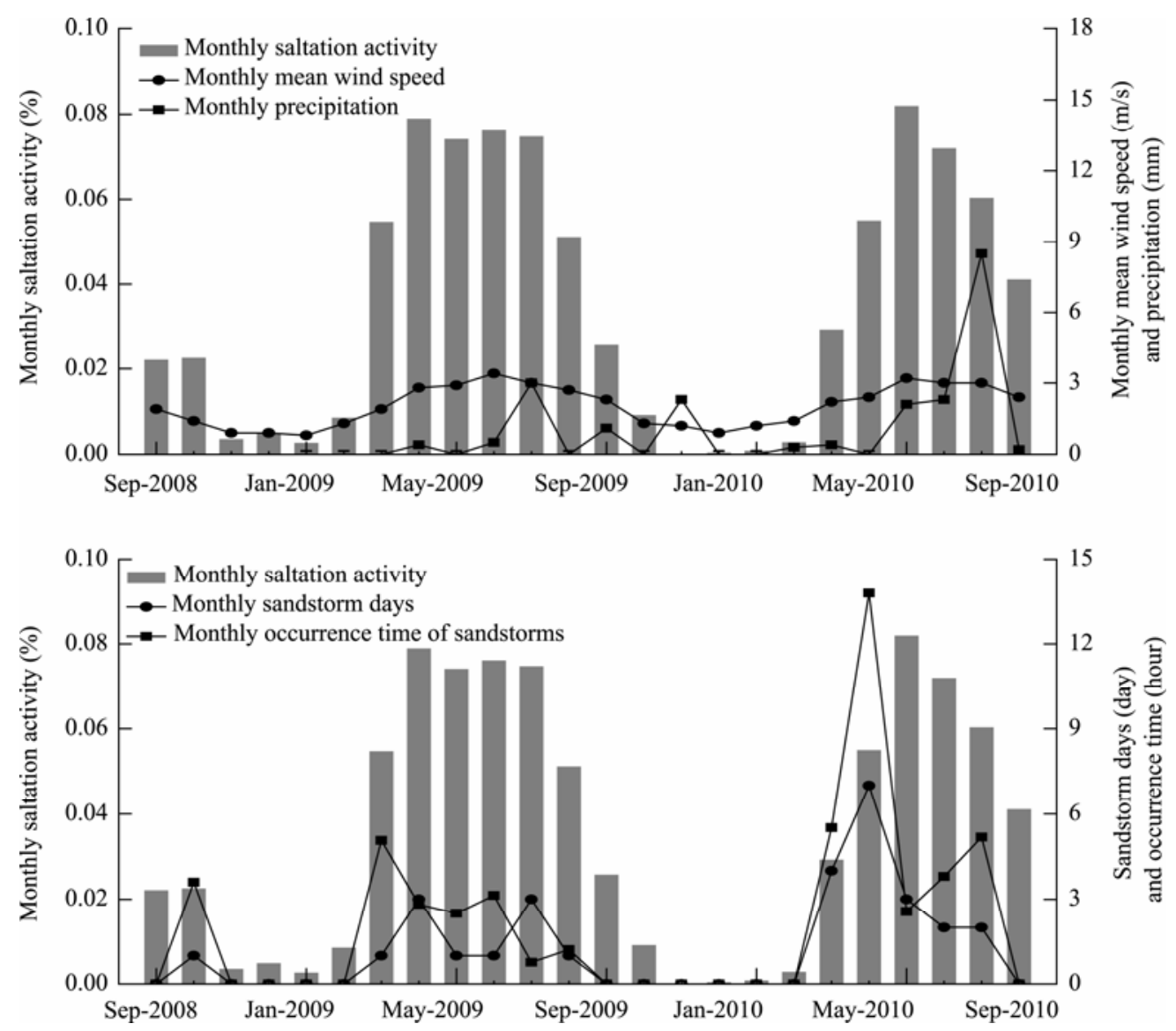

Fig. 5 Monthly saltation activity and its relationships with monthly mean wind speed, monthly precipitation, monthly occurrence time of sandstorms at Tazhong 
rence time of sandstorms. The correlation coefficient $\mathrm{R}^{2}$ is $0.885,0.076,0.318$ and 0.196 , respectively (Fig. 6). The poor correlation between saltation activity and precipitation indicates that precipitation does not appear to be significant in reducing aeolian transport in an arid region as Tazhong, and wind plays a main role in aeolian transport. This seems to be in contradiction with the result of relationship between daily saltation activity and relative humidity. Actually, there is no contradiction between the two results. From Fig. 5, we can know that the precipitation in the whole observation period is only $21.1 \mathrm{~mm}$ (mean annual value is $25.0 \mathrm{~mm}$ ), while the evaporation is up to $8,010.5 \mathrm{~mm}$ (data not shown) in the whole observation period. Comparing with the evaporation, the precipitation is negligible. In addition, about $68.7 \%$ of the precipitation is concentrated in summer, and only $44.0 \%$ of saltation activity occurs in summer. So the correlation is poor between saltation activity and precipitation, while relative humidity has significant hourly or daily variations, and it can bring hourly or daily variations of critical threshold, and then impact the saltation activity.

In this study, the saltation activity is poorly corre-
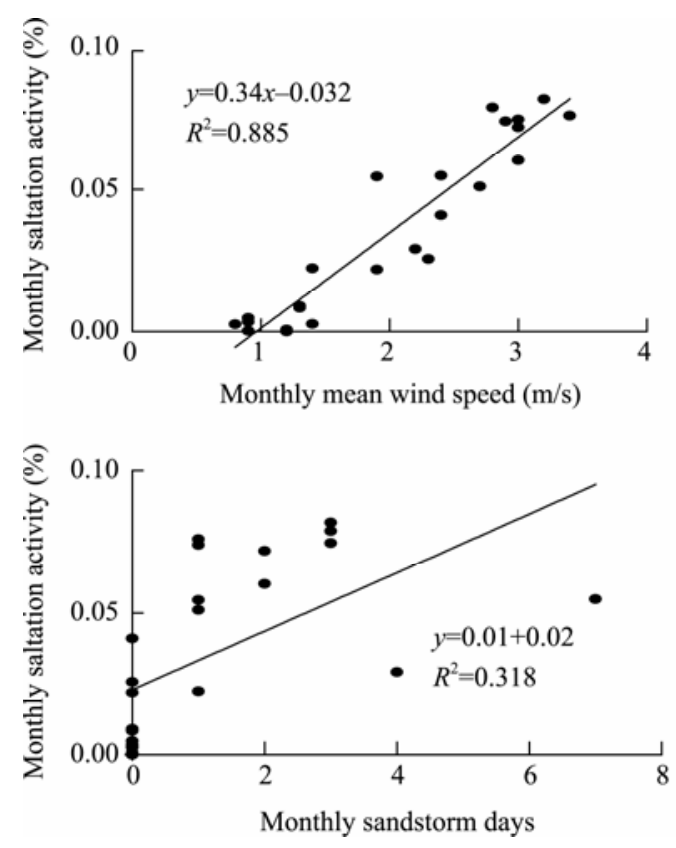

lated with sandstorm days and occurrence time of sandstorms too, indicating most of the saltation activity occurs on non-sandstorm days. Sandstorms can cause serious aeolian sand transport, but its production always needs strong weather process, while the saltation activity can occur when the local environmental conditions are satisfied.

\subsection{Seasonal saltation activity}

A seasonal summary of saltation activity and associated environmental conditions was presented in Table 3. The values of precipitation, wind speed, relative humidity, ground temperature, sandstorm days and its occurrence time represent the totals or the averages taken over an entire season. The results suggest that the ground surface at Tazhong is more erodible during spring and summer when winds are strong, with high ground temperatures and generally low humidity. The whole top 4 values of seasonal saltation activity were recorded during spring and summer. The spring in 2009 is especially active with a total of 548,311 saltation seconds and a seasonal saltation activity of 0.0689 .
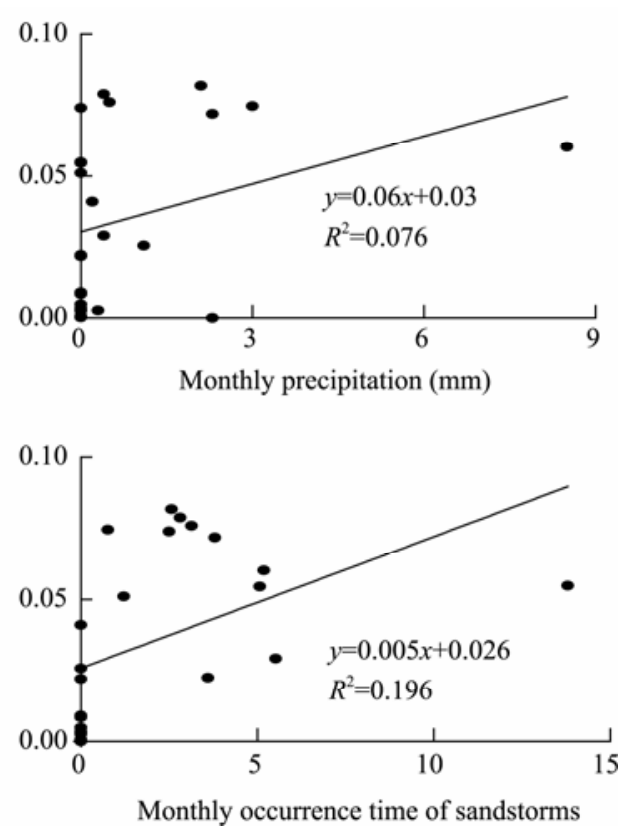

Fig. 6 Correlation analyses between monthly saltation activity, monthly mean wind speed, monthly precipitation, and monthly occurrence time of sandstorms at Tazhong 
Table 3 Seasonal saltation activity and environmental conditions at Tazhong

\begin{tabular}{|c|c|c|c|c|c|c|c|c|}
\hline Season & $\begin{array}{l}\text { Total } \\
\text { precipitation } \\
(\mathrm{mm})\end{array}$ & $\begin{array}{c}\text { Mean wind } \\
\text { speed } \\
(\mathrm{m} / \mathrm{s})\end{array}$ & $\begin{array}{l}\text { Average } \\
\text { relative } \\
\text { humidity } \\
(\%) \\
\end{array}$ & $\begin{array}{l}\text { Ground } \\
\text { temperature } \\
\left({ }^{\circ} \mathrm{C}\right)\end{array}$ & $\begin{array}{c}\text { Sandstorm days } \\
\text { (day) }\end{array}$ & $\begin{array}{l}\text { Occurrence time } \\
\text { of sandstorm } \\
\text { (hour) }\end{array}$ & $\begin{array}{c}\text { Total } \\
\text { saltation } \\
\text { seconds (s) }\end{array}$ & $\begin{array}{l}\text { Seasonal } \\
\text { saltation } \\
\text { activity }\end{array}$ \\
\hline Autumn of 2008 & 0.0 & 1.4 & 32.1 & 15.0 & 1 & 3.6 & 125,549 & 0.01597 \\
\hline Winter of 2008-2009 & 0.0 & 1.0 & 42.2 & -3.2 & 0 & 0.0 & 39,714 & 0.00511 \\
\hline Spring of 2009 & 0.4 & 2.5 & 14.6 & 22.2 & 5 & 10.4 & 548,311 & 0.06898 \\
\hline Summer of 2009 & 3.5 & 3.0 & 17.1 & 34.9 & 5 & 5.1 & 533,266 & 0.06709 \\
\hline Autumn of 2009 & 3.4 & 1.6 & 30.3 & 14.9 & 0 & 0.0 & 90,545 & 0.01152 \\
\hline Winter of 2009-2010 & 0.3 & 1.2 & 57.9 & -3.7 & 0 & 0.0 & 8,729 & 0.00112 \\
\hline Spring of 2010 & 2.5 & 2.6 & 23.9 & 20.2 & 14 & 21.9 & 438,941 & 0.05522 \\
\hline Summer of 2010 & 11.0 & 2.8 & 24.9 & 35.2 & 4 & 9.0 & 456,997 & 0.05749 \\
\hline
\end{tabular}

Saltation activity is often at a low value during winter. Only 8,729 saltation seconds were recorded for the entire winter of 2009-2010, which yields a seasonal saltation activity of 0.001 . A seasonal saltation activity value of as low as 0.005 was also recorded for the winter of 2008-2009. Relative humidity is the highest and ground temperature is the lowest during winter. High relative humidity and low ground temperature generally indicate a surface with a high threshold wind erosion condition (Stout, 2010). Nevertheless, weak wind speed during winter coupled with a high threshold condition contributed to low saltation activity during this period.

There can be significant differences in the saltation activity from one year to the next. These data suggest that saltation seconds are 1,246,840 with an annual saltation activity of 0.0395 during 2008-2009. Saltation seconds for 2009-2010 is 995,212 with an annual saltation activity of 0.0316 . Overall, the results suggest that saltation activity rarely accounts for more than $3 \%$ of the total time within a year at Tazhong.

\section{Discussion}

Two years of continuous monitoring of saltation activity have been developed on a level sand surface at Tazhong by using a piezoelectric saltation sensor, which allows the number of seconds with active sand movement within a given sampling interval to be counted and the number of saltation seconds to be summed for each specific day over a period of months to provide a relative measure of saltation activity. The results provide a detailed view of the variations in saltation activity. Compared with the variations of wind speed, relative humidity and other meteorological conditions, the variation characteristics of the saltation activity at each scale are rational and believable, which indicates that the Sensit has better applicability to monitor the aeolian activity in the Taklimakan Desert, and this technique effectively allows the variations of saltation to be defined with great precision.

From the variations of saltation activity, daily wind speed, relative humidity and the poor correlation between saltation activity and precipitation, we can conclude that wind plays a key role in aeolian transport in such an arid region as Tazhong. However, relative humidity is an unneglectable factor in arid regions, which can change topsoil moisture, inter-particle forces and critical threshold, and indirectly impact the saltation activity (Ravi et al., 2004; Ravi and D'Odorico, 2005). We should carry out more detailed researches on the effect of relative humidity on the saltation activity in future work.

Compared with previous results (Stout, 2003; de Oro and Buschiazzo, 2009), the saltation activity is higher and the surface is more erodible with lower wind speeds at Tazhong. Our analyses show that the poor precipitation (the precipitation of the whole observation period is only $21.1 \mathrm{~mm}$ ), the lack of vegetation (the ground surface consists of shifting sand) and the composition of ground surface sands (mainly fine sand and very fine sand) provide the advantageous conditions for wind erosion. The differences in variations of saltation activity in different seasons or study areas may reflect the differences in natural environment and climatic factors. 


\section{Conclusions}

Overall, our experimental results suggest that hourly saltation activity can occur nearly continuously over a one-hour period during some daytime, especially sandstorm days because of winds. Most of the high hourly values occurred during daylight hours between 07:00 and 19:00 LST in March, April, May, June, July, September and October, because of higher wind speeds and lower relative humidity in those time.

The peak values of daily activity rarely exceeded 0.5 , and most of the high daily values occurred during sandstorms, too. During the whole observation period, $4.3 \%$ of all the measured days have daily saltation activity greater than 0.2 , and $12.2 \%$ greater than 0.1 , and daily saltation activity has a good power function relationship with wind speed.

High monthly saltation activity mainly occurred in April, May, June and July and these months accounted for $67.2 \%$ of the total two years. The highest monthly value is only 0.081 , recorded in May 2010. Monthly saltation activity is strongly correlated with wind speed, and is poorly correlated with precipitation, sandstorm days and occurrence time of sandstorm.

Seasonal saltation activity tended to peak during spring and summer and it is often at a minimum during winter because of meteorological conditions. The highest value is 0.0689 , recorded in the spring of 2009 , and the lowest is only 0.001 , recorded in the winter of 2009-2010.

\section{Acknowledgements}

This research was funded by the National Natural Science Foundation of China $(41175017,41175140)$ and the R \& D Special Fund for Public Welfare Industry (meteorology) (GYHY201006012, GYHY201106025).

\section{References}

Bagnold R A. 1941. The Physics of Blown Sand and Desert Dunes. London: Methuen.

Chepil W S. 1945. Dynamics of wind erosion: I. Nature of movement of soil by wind. Soil Science, 60: 305-320.

de Oro L A, Buschiazzo D E. 2009. Threshold wind velocity as an index of soil susceptibility to wind erosion under variable climatic conditions. Land Degradation \& Development, 20: 14-21.

Fryrear D W. 1995. Soil losses by wind erosion. Soil Science Society of
America Journal, 59: 668-672.

Gillette D A, Walker T R. 1977. Characteristics of airborne particles produced by wind erosion of sandy soil, high plains of west Texas. Soil Science, 123: 97-110.

Gillette D A, Fryrear D W, Xiao J B, et al. 1997. Large-scale variability of wind erosion mass flux rates at Owens Lake: I. Vertical profiles of horizontal mass fluxes of wind-eroded particles with diameter greater than $50 \mu \mathrm{m}$. Journal of Geophysical Research, 102: 25977-25987.

Huang N, Zhang Y L, D'Adamo R. 2007. A model of the trajectories and midair collision probabilities of sand particles in a steady state saltation cloud. Journal of Geophysical Research, 112, D08206, doi: 10.1029/2006JD007480.

Leenders J K, van Boxel J H, Sterk G. 2005. Wind forces and related saltation transport. Geomorphology, 71: 357-372.

Leys J F, McTainsh G H. 1996. Sediment fluxes and particle grain-size characteristics of wind-eroded sediments in southeastern Australia. Earth Surface Processes and Landforms, 21: 661-671.

Liu T S. 2009. Loess and Arid Environment. Hefei: Anhui Science and Technology Press.

McKenna-Neuman C. 2003. Effects of temperature and humidity upon the entrainment of sedimentary particles by wind. Boundary Layer Meteorology, 108: 61-89.

McKenna-Neuman C, Sanderson S. 2008. Humidity control of particle emissions in aeolian systems. Journal of Geophysical Research, 113, F02S14, doi: 10.1029/2007JF000780.

McTainsh G, Strong C. 2007. The role of aeolian dust in ecosystems. Geomorphology, 89: 39-54.

Nickling W G. 1983. Grain-size characteristics of sediment transported during dust storms. Journal of Sedimentary Research, 53: 1011-1024.

Qian Z A, Song M H, Li W Y. 2002. Analyses on distributive variation and forecast of sand-dust storms in recent 50 years in North China. Journal of Desert Research, 22(2): 106-111.

Ravi S, D’Odorico P, Over T M, et al. 2004. On the effect of air humidity on soil susceptibility to wind erosion: the case of air-dry soils. Geophysical Research Letters, 31, L09501, doi: 10.1029/2004 GL019485.

Ravi S, D’Odorico P. 2005. A field-scale analysis of the dependence of wind erosion threshold velocity on air humidity. Geophysical Research Letters, 32, L21404, doi: 10.1029/2005GL023675.

Sankey J B, Germino M J, Glenn N F. 2009. Relationships of post-fire aeolian transport to soil and atmospheric conditions. Aeolian Research, 1: 75-85.

Schönfeldt H J, von Löwis S. 2003. Turbulence-driven saltation in the atmospheric surface layer. Meteorologische Zeitschrift, 12: 257-268

Sensit Company, 2007. Technical Description for the New Model H11-LIN. Portland: Sensit Company, 13-14.

Shao Y P. 2008. Physics and Modelling of Wind Erosion. New York: 
Springer Science + Business Media.

Sterk G, Spaan W P. 1997. Wind erosion control with crop residues in the Sahel. Soil Science Society of America Journal, 61: 911-917.

Sterk G, Jacobs A F G, van Boxel J H. 1998. The effect of turbulent flow structures on saltation sand transport in the atmospheric boundary layer. Earth Surface Processes and Landforms, 23: $877-887$.

Stout J E, Zobeck T M. 1997. Intermittent saltation. Sedimentology, 44: 959-970.

Stout J E. 2003. Seasonal variations of saltation activity on a high plains saline playa: Yellow Lake, Texas. Physical Geography, 1: 61-76.

Stout J E. 2007. Simultaneous observations of the critical aeolian threshold of two surfaces. Geomorphology, 85: 3-16.

Stout J E. 2010. Diurnal patterns of blowing sand. Earth Surface Process and Landforms, 35: 314-318.

Sun J M, Liu T S. 2006. The age of the Taklimakan Desert. Science, 312: 1621.

van Boxel J H, Arens S M, van Dijk P M. 1999. Aeolian processes across transverse dunes. I: Modelling the air flow. Earth Surface Processes and Landforms, 24: 255-270.

Wang S G, Dong G R, Chen H Z, et al. 2000. Advances in studying sand-dust storms of China. Journal of Desert Research, 20(4): 349-356.

Yang X H, Xu X L, He Q, et al. 2011. Sand flux estimation during a sand-dust storm at Tazhong area of Taklimakan Desert, China. Journal of Arid Land, 3: 199-205.

Yang X H, He Q, Ali M, et al. 2012. A Field Experiment on Dust Emission by Wind Erosion in the Taklimakan Desert. Acta Meteorologica Sinica, 26(2): 241-249.

Zhao T L, Gong S L, Zhang X Y, et al. 2006. A simulated climatology of Asian dust aerosol and its transpacific transport. Part I: Mean climate and validation. Journal of Climate, 19: 88-103.

Zheng X J, Huang N, Zhou Y H. 2003. Laboratory measurement of electrification of wind-blown sands and simulation of its effect on sand saltation movement. Journal of Geophysical Research, 108: 4322-4331.

Zheng X J, He L H, Wu J J. 2004. Vertical profiles of mass flux for windblown sand movement at steady state. Journal of Geophysical Research, 109, B01106, doi: 10.1029/2003JB002656.

Zheng X J, Xie L, Zou X Y. 2006. Theoretical prediction of liftoff angular velocity distributions of sand particles in windblown sand flux. Journal of Geophysical Research, 111, D11109, doi: 10.1029/2005JD006164.

Zhou Z J, Wang X W, Niu R Y. 2002. Climate characteristics of sandstorm in China in recent 47 years. Journal of Applied Meteorological Science, 13(2): 193-200.

Zou X Y, Wang Z L, Hao Q Z, et al. 2001. The distribution of velocity and energy of saltating sand grains in a wind tunnel. Geomorphology, 36: 155-165. 